\title{
Isolation of a genetically accessible thermophilic xylan degrading bacterium from compost
}

\author{
Martinus J. A. Daas ${ }^{1}$, Antonius H. P. van de Weijer ${ }^{1}$, Willem M. de Vos ${ }^{1}$, John van der Oost ${ }^{1}$ \\ and Richard van Kranenburg ${ }^{1,2^{*}}$
}

\begin{abstract}
Background: Due to the finite nature of global oil resources we are now faced with the challenge of finding renewable resources to produce fuels and chemicals in the future. Lactic acid has great potential as a precursor for the production of bioplastics alternatives to conventional plastics. Efficient lactic acid fermentation from non-food lignocellulosic substrates requires pretreatment and saccharification to generate fermentable sugars. A fermentation process that requires little to no enzyme additions, i.e. consolidated bioprocessing would be preferred and requires lactic acid-producing organisms that have cellulolytic and/or hemicellulolytic activity.

Results: To obtain candidate production strains we have enriched and isolated facultative anaerobic (hemi) cellulolytic bacterial strains from compost samples. By selecting for growth on both cellulose and xylan, 94 Geobacillus strains were isolated. Subsequent screening for lactic acid production was carried out from C6 and C5 sugar fermentations and a selection of the best lactic acid producers was made. The denitrifying Geobacillus thermodenitrificans T12 was selected for further research and was rendered genetically accessible. In fermentations on a mixture of glucose and xylose, a total of $20.3 \mathrm{~g}$ of lactic acid was produced with a yield of $0.94 \mathrm{~g}$ product/g sugar consumed. In addition, strain T12 is capable of direct conversion of beech wood xylan to mainly lactic acid in minimal media.
\end{abstract}

Conclusions: We have demonstrated that G. thermodenitrificans $\mathrm{T} 12$ is genetically accessible and produces lactic acid as its main fermentation product on glucose, xylose and a mixture thereof. Strain T12 was additionally used for the direct conversion of xylan to lactic acid. The genetic accessibility of the T12 strain provides a solid basis for the development of this strain into a host for consolidated bioprocessing of biomass to lactic acid.

Keywords: Geobacillus, Thermophile, Compost, Xylan, CMC, Lactic acid, Electroporation, Fermentation

\section{Background}

The increasing consciousness regarding the sustainability of our current life standards has led to the accelerating development of alternative production strategies for fuels, energy and chemicals [1]. Lactic acid is an organic acid that can be used as building block for poly lactic acid (PLA) [2]. Petrochemically produced lactic acid always yields a racemic mixture of both $\mathrm{D}$ - and L-lactic acid which results in a lower thermostability of the PLA

\footnotetext{
*Correspondence: richard.vankranenburg@wur.nl

${ }^{1}$ Laboratory of Microbiology, Wageningen University, Stippeneng 4, 6708 WE Wageningen, The Netherlands

Full list of author information is available at the end of the article
}

polymer in comparison to its optically pure counterpart derived from microbial production. Microbial production of lactic acid currently dominates the chemical synthesis alternative; however, the efficiency largely depends on the substrate, microbe and mode of production. In recent years the use of lignocellulosic or non-edible biomass as a resource has gained much interest as it does not compete with the food and feed industry. However, use of this type of substrate requires costly saccharolytic enzymes for successful conversion to fermentable sugars [3]. Consolidated bioprocessing (CBP) is a method designed to exclude such enzymes and thus optimise lignocellulosic conversion in the most economically feasible 
way. It is believed that this mode of integration can result in a process four times more cost-efficient even when compared to simultaneous saccharification and fermentation [4].

In the last decades substantial efforts have been made to isolate and engineer organisms for the conversion of lignocellulosic substrates. The search for suitable saccharolytic organisms even from the most extreme and remote spots on earth has led to the discovery of many novel isolates [5, 6]. Among these are isolates from the genus Geobacillus, a versatile group of thermophilic facultative anaerobic bacteria [7]. Geobacillus are Gram-positive, rod-shaped bacteria with the ability to sporulate. In recent years, this genus has gained much interest not only because of their thermostable enzymes, but also because of their ability to ferment $\mathrm{C} 6$ and $\mathrm{C} 5$ sugars simultaneously. Furthermore, several Geobacillus strains are capable of degrading xylan or cellulose [8, 9]. Xylanolytic activity is common in this genus and the responsible hemicellulose utilisation (HUS) locus, containing the majority of genes involved in the hemicellulose metabolism, has been described in detail elsewhere [10]. Cellulolytic activity has been demonstrated only in a few studies [11-13]. In addition, Geobacillus strains have been proven to be useful for heterologous expression of a variety of proteins $[14,15]$. Nevertheless, only limited information on this genus is available, with only 18 complete genome sequences in the NCBI database and only a few strains that have been proven to be readily transformable [16-18]. Moreover, genetic accessibility of (geo) bacilli seems to be strain-specific $[16,17]$. Because the lack of knowledge of the Geobacillus species is considered to be one of the main drawbacks to fully exploit members of this genus as platform organisms, more genome sequences, physiological data and improved genetic tools are required.

In this paper, we describe the isolation of novel Geobacillus strains of various species with the ability to degrade cellulose and/or xylan. The optimisation of transformation and the heterologous expression of a reporter gene are shown for one selected strain. In addition, the production of lactic acid by this strain was demonstrated on glucose, xylose and on beech wood xylan.

\section{Methods}

\section{Media and cultivation methods}

Cellulolytic thermophile vitamin medium (CTVM; based on $[14,17,19,20])$ contained per L: $8.37 \mathrm{~g}$ MOPS and salts mix consisting of $1 \mathrm{~g} \mathrm{NH}_{4} \mathrm{Cl} ; 3 \mathrm{~g} \mathrm{NaCl} ; 1.50 \mathrm{~g}$ $\mathrm{Na}_{2} \mathrm{SO}_{4} ; 0.08 \mathrm{~g} \mathrm{NaHCO} ; 1 \mathrm{~g} \mathrm{KCl} ; 1.8 \mathrm{~g} \mathrm{MgCl}_{2} \times 6 \mathrm{H}_{2} \mathrm{O}$; $0.30 \mathrm{~g} \mathrm{CaCl}_{2} \times 2 \mathrm{H}_{2} \mathrm{O}$. pH was set to 6.6 at room temperature and the medium was autoclaved for $20 \mathrm{~min}$ at $121{ }^{\circ} \mathrm{C}$, after which $1 \mathrm{~mL}$ of $\mathrm{K}_{2} \mathrm{HPO}_{4}(250 \mathrm{~g} / \mathrm{L}$; $\mathrm{pH}$ 6.6),
$10 \mathrm{~mL}$ of filter sterile $100 \times$ metal mix and $1 \mathrm{~mL}$ of filter sterile $1000 \times$ vitamin solution were added. $100 \times$ metal mix contained per liter: $1.60 \mathrm{~g} \mathrm{MnCl}_{2} \times 6 \mathrm{H}_{2} \mathrm{O}$; $0.1 \mathrm{~g} \mathrm{ZnSO}_{4} ; 0.2 \mathrm{~g} \mathrm{H}_{3} \mathrm{BO}_{3} ; 0.01 \mathrm{~g} \mathrm{CuSO}_{4} \times 5 \mathrm{H}_{2} \mathrm{O}$; $0.01 \mathrm{~g} \mathrm{Na}_{2} \mathrm{MoO}_{4} \times 2 \mathrm{H}_{2} \mathrm{O} ; 0.1 \mathrm{~g} \mathrm{CoCl}_{2} \times 6 \mathrm{H}_{2} \mathrm{O} ; 0.7 \mathrm{~g}$ $\mathrm{FeSO}_{4} \times 7 \mathrm{H}_{2} \mathrm{O} ; 5 \mathrm{~g} \mathrm{CaCl}_{2} \times 2 \mathrm{H}_{2} \mathrm{O} ; 20 \mathrm{~g} \mathrm{MgCl}_{2} \times 6 \mathrm{H}_{2} \mathrm{O}$. $1000 \times$ vitamin mix contained per L: $0.1 \mathrm{~g}$ thiamine; $0.1 \mathrm{~g}$ riboflavin; $0.5 \mathrm{~g}$ nicotinic acid; $0.1 \mathrm{~g}$ panthothenic acid; $0.5 \mathrm{~g}$ pyridoxamine, $\mathrm{HCl} ; 0.5 \mathrm{~g}$ pyridoxal, $\mathrm{HCl} ; 0.1 \mathrm{~g}$ D-biotin; $0.1 \mathrm{~g}$ folic acid; $0.1 \mathrm{~g} p$-aminobenzoic acid; $0.1 \mathrm{~g}$ cobalamin.

LB2 contains per liter: $10 \mathrm{~g}$ tryptone (Oxoid), $5 \mathrm{~g}$ yeast extract (Roth), $10 \mathrm{~g}$ sodium chloride and salts mix consisting of $1 \mathrm{~g} \mathrm{NH}_{4} \mathrm{Cl} ; 3 \mathrm{~g} \mathrm{NaCl} ; 1.50 \mathrm{~g} \mathrm{Na}_{2} \mathrm{SO}_{4}$; $0.08 \mathrm{~g} \mathrm{NaHCO}_{3} ; 1 \mathrm{~g} \mathrm{KCl} ; 1.8 \mathrm{~g} \mathrm{MgCl}_{2} \times 6 \mathrm{H}_{2} \mathrm{O} ; 0.30 \mathrm{~g}$ $\mathrm{CaCl}_{2} \times 2 \mathrm{H}_{2} \mathrm{O}$. pH was set to 6.6 at room temperature and the medium was autoclaved for $20 \mathrm{~min}$ at $121{ }^{\circ} \mathrm{C}$, after which $10 \mathrm{~mL}$ of $\mathrm{K}_{2} \mathrm{HPO}_{4}(250 \mathrm{~g} / \mathrm{L})$ was added.

Minimal Media (MM) contained per liter: $0.52 \mathrm{~g}$ $\mathrm{K}_{2} \mathrm{HPO}_{4} ; 0.23 \mathrm{~g} \mathrm{KH}_{2} \mathrm{PO}_{4} ; 0.5 \mathrm{~g} \mathrm{NH}_{4} \mathrm{NO}_{3}$ (MMy) or $0.3 \mathrm{~g}$ $\mathrm{NH}_{4} \mathrm{Cl}(\mathrm{MMy}+)$. After autoclaving, $1 \mathrm{~mL}$ of the following $1000 \times$ concentrated sterile stocks were added: Nitrilotriacetic acid $(200 \mathrm{~g} / \mathrm{L}) ; \mathrm{MgSO}_{4} \times 7 \mathrm{H}_{2} \mathrm{O}(145.44 \mathrm{~g} / \mathrm{L})$; $\mathrm{CaCl}_{2} \times 2 \mathrm{H}_{2} \mathrm{O}(133.78 \mathrm{~g} / \mathrm{L}) ; \mathrm{FeSO}_{4} \times 7 \mathrm{H}_{2} \mathrm{O}(11.12 \mathrm{~g} / \mathrm{L})$.

For CTVMy/MMy medium, $0.5 \mathrm{~g} / \mathrm{L}$ yeast extract (Roth) was added to the medium and CTVMy+/MMy+ contains $5 \mathrm{~g} / \mathrm{L}$ yeast extract (Roth).

Glycerol stocks of cultures were made by adding $500 \mu \mathrm{L}$ of sterilised $60 \%$ glycerol to $1.5 \mathrm{~mL}$ culture, in a $2 \mathrm{~mL}$ cryogenic vial (Corning). Stocks were stored at $-80^{\circ} \mathrm{C}$.

In all plate and tube cultures, carbon substrates were used in a concentration of $10 \mathrm{~g} / \mathrm{L}$ unless stated otherwise. Carbon sources were autoclaved separately with xylose being filter sterilised.

For plate cultures, $5 \mathrm{~g} / \mathrm{L}$ gelrite (Roth) was added. Anaerobic cultivation of plates was done in an anaerobic jar (HP0011, Oxoid) containing an AnaeroGen sachet (AN0035, Oxoid).

All wild-type strains were isolated and cultured at $65{ }^{\circ} \mathrm{C}$. Strains harbouring the pNW33n plasmid are always cultured at $55{ }^{\circ} \mathrm{C}$ to maintain the plasmids replication. Cultures in liquid media are shaken at $150 \mathrm{RPM}$ unless stated otherwise.

\section{Sampling}

Samples were collected from both a mature and an active compost heap at ReCom Ede (NL). The temperature of the mature compost was around $35^{\circ} \mathrm{C}$ at the sampling site on top of the compost heap and around $65{ }^{\circ} \mathrm{C}$ for the active compost heap which was sampled at a depth of $30 \mathrm{~cm}$. Both heaps were semi-anaerobic due to mixing once every week. The sampling site of the 1st isolation was aerobic since the sampling was done on top of the 
compost. Samples were taken by scraping compost into a plastic jar and were used to inoculate immediately after transport to the lab at room temperature. The sample of the 2nd isolation was kept under anaerobic conditions during transport using an Oxoid AnaeroGen sachet in a sealed anaerobic box.

\section{Isolation procedure}

For the first isolation, $25 \mathrm{~g}$ mature compost was added to $250 \mathrm{~mL}$ of CTVM-CMC in a $500 \mathrm{~mL}$ flask and shaken for $3 \mathrm{~h}$ at $150 \mathrm{rpm}$ at $65^{\circ} \mathrm{C}$. After $3 \mathrm{~h}$, compost was sieved with a $3 \mathrm{~mm}$ pore size filter and dilution series were plated on CTVMy-CMC and CTVM-CMC and grown aerobically for $72 \mathrm{~h}$. Subsequently, single colonies were picked and transferred to fresh plates containing either CTVMy-CMC or CTVM-CMC (according to their isolation plate). Identical plates lacking CMC were used as negative control. Grown isolates were transferred twice to assay consistent growth and eliminate false-positives. These false-positives present colonies that possibly grow on the degradation products produced by surrounding colonies. By transferring colonies to fresh plates we were able to eliminate those from the selection. Remaining isolates were then grown anaerobically for $96 \mathrm{~h}$ to assay their potential of anaerobic growth. The remaining isolates were used to obtain pure cultures and afterwards stored in $15 \%$ glycerol at $-80^{\circ} \mathrm{C}$.

In the second isolation, $10 \mathrm{~g}$ active compost was inoculated into $100 \mathrm{~mL}$ of CTVM in a $500 \mathrm{~mL}$ beaker and stirred for $5 \mathrm{~min}$ at room temperature. Due to the active state of the compost, oxygen levels are believed to be limited at the sampling site. Therefore, the isolation of microorganisms from this sample was initiated under anaerobic conditions to mimic the site of sampling. Dilution series were plated on CTVMy-CMC and CTVMCMC and grown anaerobically for $72 \mathrm{~h}$. Subsequently, single colonies were picked and each colony was streaked to plates containing CTVMy or CTVM (according to their isolation plate) with or without CMC and grown anaerobically at $65{ }^{\circ} \mathrm{C}$ for $168 \mathrm{~h}$ (7 days). Isolates lacking growth on the negative controls were transferred twice more to CTVM(y)-CMC plates to assay consistent growth and eliminate false-positives. Pure cultures were obtained on CTVMy-glc plates and subsequently stored in $15 \%$ glycerol stocks at $-80^{\circ} \mathrm{C}$.

\section{$16 \mathrm{~S}$ rRNA-encoding gene identification and phylogenetic analysis}

Single colonies were picked from plates and inoculated to pre-warmed CTVMy medium with $1 \% \mathrm{w} / \mathrm{v}$ glucose. When cultures reached the exponential phase $\left(\mathrm{OD}_{600}\right.$ between 0.5 and 1) $2 \mu \mathrm{L}$ was transferred to a PCR tube. PCR mix was added containing 1.25 units of DreamTaq
DNA polymerase (Fermentas), 10 $\times$ DreamTaq buffer (Fermentas), $100 \mu \mathrm{M}$ of dNTPs (Fermentas), $0.2 \mu \mathrm{M}$ of both primers GM3 (AGAGTTTGATCATGGC) and GM4 (TACCTTGTTACGACTT) and milliQ water in a total volume of $50 \mu \mathrm{L}$ [21]. PCR products were checked on $1 \%$ agarose gels and products were purified using a GeneJet PCR purification kit (Fermentas). CloneManager software was used to assemble and manually curate the GM3 and GM4 sequences into one contig after which BLASTn was used for identification against the non-redundant nucleotide collection of the NCBI database. Contigs were aligned using Mega6 [22] software and MUSCLE v3.8.31 [23] with 5 iterations and, subsequently, were trimmed to equal length using Jalview version 2.0 [24]. The 94 sequences have been submitted to NCBI under GenBank accession numbers KX113522-KX113615. A phylogenetic tree was created using the neighbor-joining method [25] and a bootstrap analysis [26] was done using 1000 replicates. Type strains used in the phylogenetic tree were derived from the following GenBank accession numbers: NR_043021.1 (G. thermodenitrificans DSM 465), NR_043022.1 (G. thermoglucosidasius DSM 2542), NR_028708.1 (G. caldoxylosilyticus DSM 12041), NR_115285.1 (G. kaustophilus DSM 7263), FN428684.1 (G. thermoleovorans DSM 5366), NZ_ CP010052.1 (B. subtilis DSM 402).

\section{Selection}

All pure strains were inoculated from glycerol stocks to plates containing CTVMy-CMC and CTVMy-xylan and subsequently incubated anaerobically for $48 \mathrm{~h}$. Plates were then washed using milliQ water to remove all cells and subsequently stained for $5 \mathrm{~min}$ using a $0.1 \%(\mathrm{w} / \mathrm{w})$ Congo red dye. After staining, plates were de-stained for $15 \mathrm{~min}$ using $1 \mathrm{M} \mathrm{NaCl}$ under constant swirling. Clearing zones were identified visually and graded using a 4 step scale ranging from 0 to 4 with zero being no visible clearing zone and four representing the biggest clearing zone.

Screening on fermentation products was carried out in duplicate in $15 \mathrm{~mL}$ Greiner tubes with a total volume of $10 \mathrm{~mL}$ containing CTVMy medium at an initial $\mathrm{pH}$ of 6.5 with cellobiose or xylose as carbon substrate. Tubes were inoculated from plate colonies and incubated at $65^{\circ} \mathrm{C}$ for $48 \mathrm{~h}$ with agitation at $50 \mathrm{rpm}$. After $48 \mathrm{~h}$ samples were taken for HPLC analysis on fermentation product profiles and quantities. Strains were then ranked based on highest total amount of products and highest total lactic acid formed. The average score of both cellobiose and xylose duplicates were combined and best scoring strains were then compared to the selected isolates from the Congo red plate assay (data not shown). Isolates with high enzymatic activity for either CMC and/or xylan combined with an above average ranking in the fermentation assay were selected to examine their genetic accessibility. 
Genetic accessibility and heterologous expression of the pheB reporter gene

Three isolates closely related to G. thermodenitrificans (99\%), G. caldoxylosilyticus (100 \%) and G. thermoleovorans (99\%) were selected to evaluate genetic accessibility by electroporation. Strains were subjected to transformation in triplicate according to the protocols for Geobacillus described previously [14, 27] using the pNW33n plasmid isolated from E. coli $\mathrm{dH} 5 \alpha$. After $2 \mathrm{~h}$ recovery at $60{ }^{\circ} \mathrm{C}$, electroporated cells were spread on LB2 plates containing $7 \mu \mathrm{g} / \mathrm{mL}$ of chloramphenicol and incubated for $24 \mathrm{~h}$ at $60^{\circ} \mathrm{C}$. Colonies that appeared within $48 \mathrm{~h}$ were subjected to PCR as described above to verify the presence of plasmid pNW33n inside the cells.

Optimisation of the transformation protocol was performed on strain T12. Three concentrations $(0,0.25$ and $2.5 \mathrm{~g} / \mathrm{L})$ of $\mathrm{K}_{2} \mathrm{HPO}_{4}$ in the growth medium were used and washing of the cells was done 2 times with $50 \mathrm{~mL}$ of milliQ water followed by 2 washing steps, of 25 and $10 \mathrm{~mL}$, respectively, using $10 \%$ (v/v) glycerol [28].

As a demonstration of genetic accessibility, we cloned the reporter gene pheB, derived from G. stearothermophilus DSM 6285 (GenBank accession no. DQ146476.2) into strain T12. The $p h e B$ gene was synthesised by GeneArt (Thermo Scientific) as an expression construct using the constitutive promoter PuppT12. Promoter Pupp T12 is derived from the upstream region (100nt) of the uracil phosphoribosyltransferase gene from T12 (Additional file 1: Figure S1). The promoter together with the $p h e B$ reporter gene were cloned to pNW33n between the Acc65I and PstI restriction sites. Activity of the reporter gene was tested by spraying colonies with $100 \mathrm{mM}$ catechol followed by incubation at $55^{\circ} \mathrm{C}$ for $5 \mathrm{~min}$.

\section{Fermentations}

Fermentations were performed in an Eppendorf DASGIP parallel bioreactor system or an Applikon fermentor system. In the Eppendorf DASGIP parallel bioreactor system glass reactors of $1.4 \mathrm{~L}$ and a working volume of $0.5 \mathrm{~L}$ was used with Dasgip control 4.0 to control the process. Glass reactors of $2 \mathrm{~L}$ and a working volume of $1 \mathrm{~L}$ were used in the Applikon fermentor system with BioXpert V2 for control. The conditions were as follows: Temperature was controlled at $65^{\circ} \mathrm{C}, \mathrm{pH}$ at 7.0 by addition of $3 \mathrm{M}$ $\mathrm{KOH}$ and the stirring speed was $150 \mathrm{rpm}$. Antifoam 204 (Sigma-Aldrich) was added as required.

Pre-cultures were grown overnight from glycerol stock in $10 \mathrm{~mL}$ medium in a $50 \mathrm{~mL}$ tube at $65^{\circ} \mathrm{C}$ and $150 \mathrm{rpm}$. The next morning $3 \mathrm{~mL}$ was transferred to $50 \mathrm{~mL}$ of medium in a $250 \mathrm{~mL}$ baffled Erlenmeyer and grown for $2 \mathrm{~h}$ before $2 \%(\mathrm{v} / \mathrm{v})$ was inoculated to the reactor. Samples of $2 \mathrm{~mL}$ were taken for off-line OD-measurements by determining the turbidity at $600 \mathrm{~nm}$. Concentrations of sugar and fermentation products were determined by HPLC.

\section{HPLC}

Sugars and fermentation products were measured using an ICS5000 HPLC system from Thermo Scientific equipped with a Dionex DP pump, Dionex AS-AP autosampler, Dionex VWD UV detector operated at $210 \mathrm{~nm}$ and Shodex RI detector at $35{ }^{\circ} \mathrm{C}$. An Aminex HPX-87H cation-exchange column was used with a mobile phase of $8 \mathrm{mM} \mathrm{H}_{2} \mathrm{SO}_{4}$ and was operated at $0.8 \mathrm{~mL} / \mathrm{min}$ and $60^{\circ} \mathrm{C}$. All samples were diluted with $10 \mathrm{mM}$ dimethyl sulfoxide in $4 \mathrm{mM} \mathrm{H}_{2} \mathrm{SO}_{4}$ in a ratio of 5:1 sample/internal standard.

\section{Results}

To isolate facultative anaerobic thermophiles capable of degrading cellulose and/or xylan, mature and active compost of plant materials were sampled with temperatures of 35 and $65{ }^{\circ} \mathrm{C}$, respectively, at time of isolation.

\section{Isolation}

The mature compost was suspended in CTVM medium at $65{ }^{\circ} \mathrm{C}$ and dilution series were plated on CTVM-CMC with or without $0.5 \mathrm{~g} / \mathrm{L}$ yeast extract at $65{ }^{\circ} \mathrm{C}$ to select for thermophiles. Addition of yeast extract resulted in approximately 1.5 times more colonies. From both media, 130 isolates were picked and grown aerobically for almost 4 days. Clear differences in growth speed/lag time and recovery rate were observed in favour of plates containing yeast extract (Additional file 2: Table S1). The control plates without carbon source (CTVM and CTVMy) showed no or very little growth of the isolates, indicating that $\mathrm{CMC}$ was required to obtain the growth monitored. Growth of some isolates became visible later than that of others, which may indicate either slower growth rates or an elongated lag phase, due to growth on degradation products of other isolates. When isolates were streaked again to fresh medium, lag time was shortened and the amount of recovered isolates decreased, possibly due to the elimination of false-positives (Additional file 2: Table S1).

The active compost sample used in the second isolation was resuspended in CTVM medium, plated on CTVMyCMC medium and incubated anaerobically at $65{ }^{\circ} \mathrm{C}$ for $72 \mathrm{~h}$. After incubation, 130 colonies from the CTVMyCMC plates and 130 colonies from CTVM-CMC plates were isolated and subsequently transferred to fresh plates. None of the isolates from the CTVM-CMC plates were recovered and only 17 could be recovered from the CTVMy-CMC plates. Further transfers demonstrated that maintaining the isolates on CMC medium was often unsuccessful and revival from glycerol stocks was even more challenging (Table 1). 
Table 1 Isolate numbers recovered after multiple transfers on both CTVM-CMC and CTVMy-CMC media

\begin{tabular}{lllcccc}
\hline Isolation round & Media & Isolates & Recovery 1st transfer & Recovery 2nd transfer & Recovery 3th transfer & Recovery -80 stock \\
\hline 1st (aerobic) & CTVM-CMC & 130 & 63 & 31 & 31 & 9 \\
\multirow{2}{*}{ 2nd (anaerobic) } & CTVMy-CMC & 130 & 99 & 79 & 79 & 79 \\
& CTVM-CMC & 130 & 0 & 0 & 0 & 0 \\
Total & CTVMy-CMC & 130 & 17 & 16 & 13 & 6 \\
\hline
\end{tabular}

From the initial 520 isolates 94 have been recovered

\section{Selection}

Pure cultures obtained from both isolation rounds were subjected to $16 \mathrm{~S}$ rRNA-encoding gene sequencing for identification. All 94 isolates belonged to the Geobacillus genus (Fig. 1). The majority, 73 of 94 isolates, were G. thermodenitrificans. The remainder was classified as $G$. thermoglucosidans (11), G. caldoxylosilyticus (8) and G. kaustophilus (2).

Further selection was based on fermentation product profiles. Isolates were pre-grown on CTVMy-glc and subsequently transferred to fresh CTVMy media containing either glucose or xylose as the carbon source. After $48 \mathrm{~h}$ fermentation products were measured by HPLC (Additional files 3, 4: Tables S2, S3). All strains produced lactic acid as their main fermentation product. Besides lactic acid, acetic acid was present in all cultures. In some cases, independent of the amount of lactic acid, ethanol and formate were also produced. Succinate production was seen in some cultures, with G. thermodenitrificans T78 showing the highest average concentration of $4.3 \mathrm{mM}$ succinic acid accounting for $19.3 \%$ (mol/ mol) of the total products (data not shown). All strains belonging to G. thermoglucosidans showed similar production profiles implying low variability within this genus in comparison to for instance G. caldoxylosilyticus. G. thermoglucosidans is highly represented in the 25 strains with the highest organic acid production titers. This is demonstrated by the presence of 10 out of 11 strains in the cellobiose fermentations ranking and 8 of 11 strains in the xylose fermentations ranking (Additional files 3, 4; Tables S2, S3). Contrary to this observation, G. thermoglucosidans is underrepresented in the ranking of the 25 best lactic acid producers with only 3 (C6) and 4 (C5) strains listed. Under such conditions G. thermodenitrificans has a more homolactic phenotype while $G$. thermoglucosidans has a more mixed acid fermentation phenotype (data not shown). The mixed acid fermentation profiles of G. thermoglucosidans are in line with a previous study that demonstrated a mixed acid fermentation profile under micro-aerobic conditions [29].

The list of strains producing the highest amounts of lactic acid from cellobiose fermentation was overlaid with the list of isolates producing most lactic acid on xylose. No isolates belonging to G. caldoxylosilyticus or G. kaustophilus appeared in both lists. In addition to the fermentation assays described above, all 94 isolates were subjected to Congo red stain after growth on CMC and beech wood xylan. About 24 strains degraded $\mathrm{CMC}$, as indicated by halo formation after staining with the Congo red dye. However, after repeated assays using Congo red it became evident that the formation of halos was highly irreproducible, although growth was similar in most cases. When grown on xylan, halos were more pronounced and a clear degradation was observed for about half of the isolates. Strain T12 showed strong and reproducible breakdown of xylan. Based on the concentrations of the products in the cellobiose and xylose fermentations, and the reproducibility of the plate assays, strains T12, T62, and T85 (all originating from the 1st isolation round) were considered the best isolates for further study.

\section{Electroporation and optimisation of transformation}

The genetic accessibility of these three selected isolates were then evaluated by electroporation performed based on protocols described previously [14, 30], with some modifications. Cells were transformed by electroporation using the E. coli-Bacillus shuttle vector pNW33n, a vector that has been widely used in thermophilic bacilli $[17$, $31,32]$. Colonies found to be chloramphenicol-resistant were streaked to fresh LB2 plates supplemented with chloramphenicol to eliminate false-positives and successful transformation was confirmed by colony PCR. Following this, plasmids were isolated from the positive clones and subjected to restriction analysis to confirm integrity, before transfer back to E. coli. While T62 and T85 did not yield any colonies, transformation of strain T12 reproducibly did. In all cases the colonies obtained for T12 were positive for plasmid uptake. Although the efficiency was low, the high reproducibility provided the opportunity for optimisation. Different culture media and wash protocols were evaluated (Table 2), and a combination of reduced concentrations of $\mathrm{K}_{2} \mathrm{HPO}_{4}$ with a wash protocol derived from [28], proved to be the best protocol with an optimum CFU/ $\mu$ g DNA of $1.7 \times 10^{4}$. The LB2 medium initially used resulted in a short pulse 


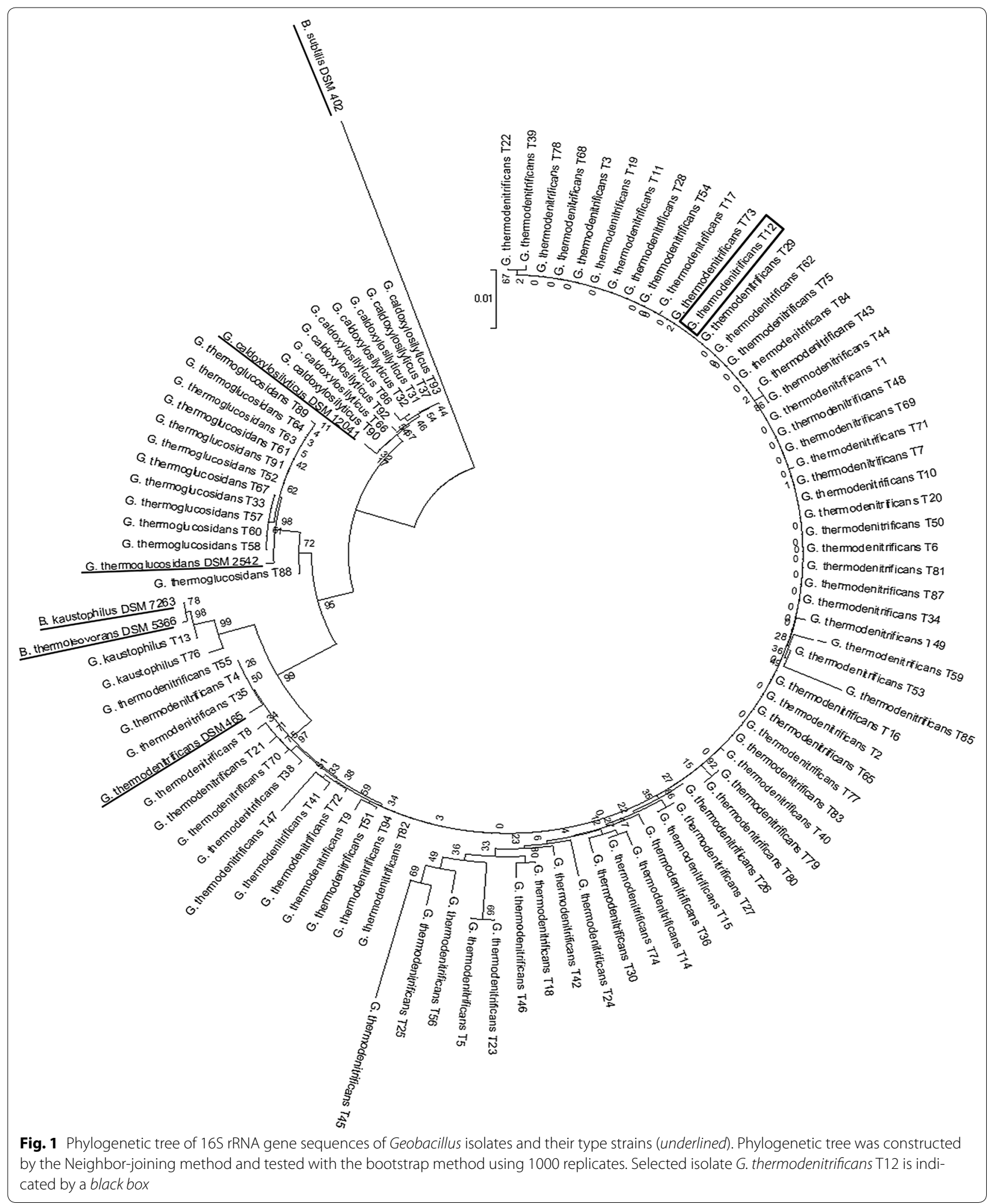

time constant of $3.7 \mathrm{~ms}$. However, changing this growth medium to a variant with a lower salt concentration resulted in an increased pulse time constant and a CFU/ $\mu \mathrm{g}$ DNA of 1240, which was in line with the results seen in previous research [17]. Consequently, decreasing the salt concentrations in the growth medium LB2 resulted 
Table 2 Overview of transformation optimisations for G. thermodenitrificans T12

\begin{tabular}{|c|c|c|c|c|c|c|c|c|c|c|}
\hline Parameter changed & Medium & Growth $^{\mathrm{a}}(\mathrm{h})$ & Final OD ${ }^{\mathbf{b}}$ & Voltage & $\Omega$ & $\mu \mathrm{F}$ & $\begin{array}{l}\text { Cuvette } \\
\text { width (mm) }\end{array}$ & $\operatorname{Ptd}^{c}(m s)$ & $\operatorname{DNA}^{d}(\mu \mathrm{g})$ & $\begin{array}{l}\text { CFU/ } \\
\mu g \text { DNA }\end{array}$ \\
\hline N.A. & $\begin{array}{l}\mathrm{LB} 2 \\
\left(2.50 \mathrm{~g} / \mathrm{L} \mathrm{K}_{2} \mathrm{HPO}_{4}\right)\end{array}$ & 2 & 1.01 & 2000 & 200 & 25 & 2 & 3.7 & 3.031 & 4 \\
\hline Medium & $\begin{array}{l}\text { LB2 } \\
\left(0.25 \mathrm{~g} / \mathrm{L} \mathrm{K}_{2} \mathrm{HPO}_{4}\right)\end{array}$ & 1.67 & 0.96 & 2000 & 200 & 25 & 2 & 5.1 & 1.613 & 1240 \\
\hline Medium & $\begin{array}{l}\text { LB2 } \\
\left(0.00 \mathrm{~g} / \mathrm{L} \mathrm{K}_{2} \mathrm{HPO}_{4}\right)\end{array}$ & 1.66 & 0.96 & 2000 & 200 & 25 & 2 & 5 & 1.613 & 22 \\
\hline Wash buffere & $\begin{array}{l}\mathrm{LB} 2 \\
\left(2.50 \mathrm{~g} / \mathrm{L} \mathrm{K}_{2} \mathrm{HPO}_{4}\right)\end{array}$ & 1.67 & 0.96 & 2000 & 200 & 25 & 2 & 5.2 & 1.613 & 19 \\
\hline Medium/wash buffer ${ }^{e}$ & $\begin{array}{l}\text { LB2 } \\
\left(0.00 \mathrm{~g} / \mathrm{L} \mathrm{K}_{2} \mathrm{HPO}_{4}\right)\end{array}$ & 1.66 & 0.96 & 2000 & 200 & 25 & 2 & 5.4 & 1.613 & 2988 \\
\hline Medium/wash buffer ${ }^{\mathrm{e}}$ & $\begin{array}{l}\text { LB2 } \\
\left(0.25 \mathrm{~g} / \mathrm{L} \mathrm{K}_{2} \mathrm{HPO}_{4}\right)\end{array}$ & 1.83 & 0.96 & 2000 & 200 & 25 & 2 & 5.5 & 1.564 & 17,071 \\
\hline \multicolumn{11}{|c|}{ a Time of growth after dilution of the overnight pre-culture } \\
\hline \multicolumn{11}{|c|}{ b Final $\mathrm{OD}_{600}$ of the culture after growth prior to the washing step } \\
\hline \multicolumn{11}{|c|}{ c Pulse time duration in milliseconds } \\
\hline \multicolumn{11}{|c|}{ d Amount of plasmid (pNW33n) DNA added for transformation } \\
\hline e Wash protocol was cha & iged to 2 times washin & g with milliQ wa & & & & & & & & \\
\hline
\end{tabular}

in the cell pellets becoming less dense, leading to loss of many cells during washing. To prevent the loss of cells, $0.25 \mathrm{~g} / \mathrm{L} \mathrm{K}_{2} \mathrm{HPO}_{4}$ was added and wash buffers were changed to milliQ water and $10 \%$ glycerol, to increase the osmotic shock that results in weakening of the bacterial cell wall. Several variables need to be balanced to obtain a successful electroporation protocol. For example with a more severe wash protocol, the cells will be weaker during electroporation, which will probably require a lower voltage to reduce further damage to the cells. Although no statistical underpinning was performed, our protocol is demonstrated to be reproducible.

To verify the potential of the T12 genetic accessibility, we introduced $p h e B$ as a reporter gene. The reporter gene pheB, derived from G. stearothermophilus DSM 6285 (GenBank accession no. DQ146476.2), encodes a heterologous catechol 2,3-dioxygenase $(\mathrm{C} 23 \mathrm{O})$. The pheB gene is demonstrated to function as a reporter gene in G. thermoglucosidans, where it has been used for the quantification of promoter strength [33]. The protein $\mathrm{C} 23 \mathrm{O}$ oxidises catechol to form 2-hydroxymuconic semialdehyde (2-HMSA) which has a bright yellow colour. Colonies harbouring the pheB expression construct can, therefore, be visualised by spraying them with $100 \mathrm{mM}$ catechol and incubating them for $5 \mathrm{~min}$ at $55^{\circ} \mathrm{C}$. A bright yellow colour was observed on all colonies harbouring the pheB expression construct, while no colour change was observed in colonies harbouring empty pNW33n plasmids (Additional file 5: Figure S2).

\section{Growth and fermentation of T12}

Fermentation characteristics of G. thermodenitrificans T12 were evaluated under micro-aerobic conditions. To determine an optimal $\mathrm{pH}$, multiple $\mathrm{pH}$-controlled fermentations were carried out in MMy media containing $30 \mathrm{~g} / \mathrm{L}$ glucose, with a pH range of 5.5-8.5. Both growth and product formation were monitored during the fermentation (data not shown) to determine the optimal conditions. Growth was observed between pH 5.5 and 7.5 , with an optimum between $\mathrm{pH} 6.5$ and 7.5. This optimal growth $\mathrm{pH}$ of 7.5 coincided with the highest amount of lactic acid production followed closely by the culture at $\mathrm{pH} 6.5$.

To assay the potential of strain T12 in converting biomass derived sugars, its fermentation products and productivity thereof, were quantified in fermentations with glucose, xylose and mixtures of these sugars as carbon source. For all carbon substrates, both MMy media (containing $0.5 \mathrm{~g} / \mathrm{L}$ yeast extract and $\mathrm{NH}_{4} \mathrm{NO}_{3}$ ) as well as $\mathrm{MMy}+$ media (containing $5 \mathrm{~g} / \mathrm{L}$ yeast extract and $\mathrm{NH}_{4} \mathrm{Cl}$ ) were evaluated (Fig. 2; Table 3). Ammonium nitrate was added to MMy medium to stimulate biomass formation [34].

The average lactic acid productivity on $30 \mathrm{~g} / \mathrm{L}$ glucose or $30 \mathrm{~g} / \mathrm{L}$ xylose, either on minimal or rich medium, did not differ significantly. However, productivities differ when comparing a single carbon source on minimal and rich medium (Table 3). Co-fermentation of both glucose and xylose was performed in both media (Fig. 2; Table 3). When MMy medium with a 2:1 ratio of glucose:xylose was used, a total of $17.9 \mathrm{~g}$ lactic acid was produced in $55 \mathrm{~h}$ with an overall yield of $0.7 \mathrm{~g}$ lactic acid/g sugar consumed. From the start of the fermentation, both glucose and xylose were consumed simultaneously though the consumption rates for xylose were lower in comparison to glucose (Table 3). Fermentations in $\mathrm{MMy}+$ medium 

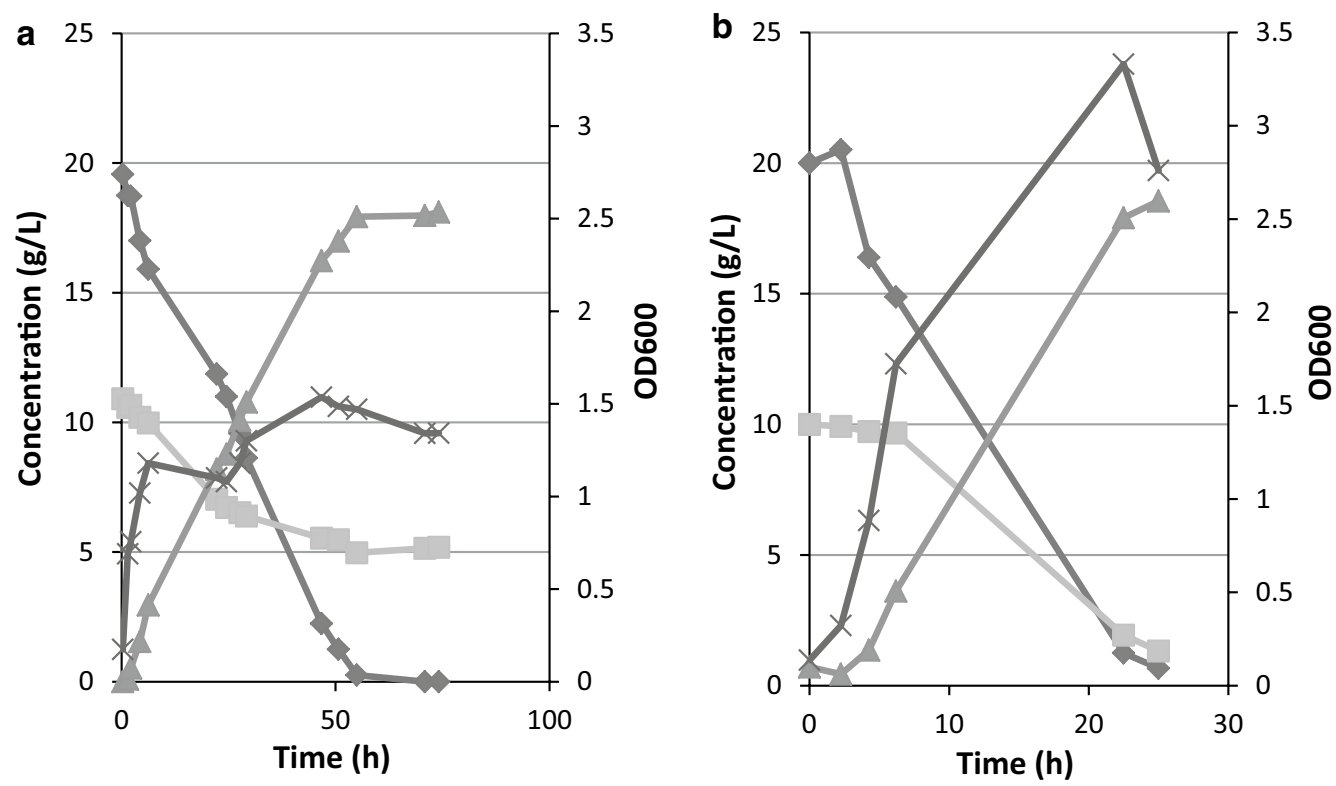

Fig. 2 Fermentations of G. thermodenitrificans T12 on a 2:1 glucose/xylose mixture. Fermentations were carried out at pH 7.0 at $150 \mathrm{rpm}$. Fermentations started with a $0.5 \mathrm{~L}$ air headspace without additional sparging and media consisted of $500 \mathrm{~mL}$ MMy (a) or MMy+(b). glucose; $\quad x y l o s e ;$ lactic acid; $\times \mathrm{OD}_{600}$

Table 3 Overview of fermentations of G. thermodenitrificans T12 on glucose, xylose and glucose/xylose mixtures

\begin{tabular}{|c|c|c|c|c|c|c|c|c|}
\hline Media & Substrate & Time (h) & Cons. (g) & $\begin{array}{l}\text { Cons. rate } \\
\text { (g/L/h) }\end{array}$ & $\begin{array}{l}\text { Lactic acid pro- } \\
\text { duction (g) }\end{array}$ & $\begin{array}{l}\text { Lactic acid } \\
\text { productivity } \\
\text { (g/L/h) }\end{array}$ & $\begin{array}{l}\text { Lactic acid } \\
\text { yield } \\
\text { (g product/g } \\
\text { substrate } \\
\text { consumed) }\end{array}$ & $\begin{array}{l}\text { Lactic acid yield } \\
\text { (\% of theoretical } \\
\text { yield) }\end{array}$ \\
\hline MMy & $30 \mathrm{~g} / \mathrm{L}$ glucose & 25.2 & 9.43 & 0.37 & 3.10 & 0.12 & 0.33 & 10.3 \\
\hline MMy & $30 \mathrm{~g} / \mathrm{L}$ xylose & 25 & 6.93 & 0.28 & 3.83 & 0.15 & 0.55 & 12.8 \\
\hline MMy & $\begin{array}{l}20 \mathrm{~g} / \mathrm{L} \text { glu- } \\
\text { cose }+10 \mathrm{~g} / \mathrm{L} \\
\text { xylose }\end{array}$ & 54.95 & $\begin{array}{c}19.87 \text { glucose } \\
6.55 \text { xylose }\end{array}$ & $\begin{array}{r}0.33 \text { glucose } \\
0.11 \text { xylose }\end{array}$ & 17.93 & 0.30 & 0.69 & 59.8 \\
\hline MMy+ & $30 \mathrm{~g} / \mathrm{L}$ glucose & 27 & 11.35 & 0.41 & 8.48 & 0.30 & 0.74 & 28.3 \\
\hline MMy+ & $30 \mathrm{~g} / \mathrm{L}$ xylose & 27 & 15.23 & 0.54 & 8.73 & 0.31 & 0.57 & 29.1 \\
\hline MMy+ & $\begin{array}{l}20 \mathrm{~g} / \mathrm{L} \text { glu- } \\
\text { cose }+10 \mathrm{~g} / \mathrm{L} \\
\text { xylose }\end{array}$ & 25 & $\begin{array}{l}14.51 \text { glucose } \\
7.05 \text { xylose }\end{array}$ & $\begin{array}{r}0.50 \text { glucose } \\
0.24 \text { xylose }\end{array}$ & 20.27 & 0.71 & 0.94 & 67.6 \\
\hline
\end{tabular}

Fermentations were carried out at $\mathrm{pH} 7.0$ at $150 \mathrm{rpm}$. Fermentations started with a $0.5 \mathrm{~L}$ air headspace without additional sparging. MMy media contained $0.5 \mathrm{~g} / \mathrm{L}$ of yeast extract, whereas $\mathrm{MMy}+$ media contained $5 \mathrm{~g} / \mathrm{L}$ of yeast extract

showed improved consumption rates, productivity and yield of lactic acid produced per amount of consumed substrate.

In all mixed sugar fermentations the xylose consumption rate was 2-3 times slower when compared to the consumption rate of glucose. To exclude the possibility that the sugar concentration is instrumental in this observation, a glucose/xylose co-fermentation was completed with equal concentrations of the two sugars $(10 \mathrm{~g} / \mathrm{L})$ in MMy medium. Observed consumption rates of $0.2 \mathrm{~g} / \mathrm{L} / \mathrm{h}$ for glucose and $0.1 \mathrm{~g} / \mathrm{L} / \mathrm{h}$ for xylose confirm that glucose is in fact favoured over xylose in co-fermentation.

The Congo Red assay showed that strain T12 was capable of degrading beech wood xylan on solid medium. To quantify its fermentation products liquid cultures with $10 \mathrm{~g} / \mathrm{L}$ beech wood xylan as carbon source were used. Fermentations were carried out in $50 \mathrm{~mL}$ Greiner tubes with different volumes of head space and $250 \mathrm{~mL}$ shake flasks to demonstrate the impact of oxygen (Fig. 3). Under micro-aerobic conditions in low nutrient 
(MMy) medium (Fig. 3a, b), lactic acid (11 mM) was the main fermentation product followed by acetic acid. In $250 \mathrm{~mL}$ baffled Erlenmeyer shake flasks using $50 \mathrm{~mL}$ culture (1:5 with more aeration), lactic acid concentration was reduced to $0.55( \pm 0.04) \mathrm{mM}$ and acetic acid increased to $19( \pm 0.04) \mathrm{mM}$ (data not shown). Use of the rich $(\mathrm{MMy}+)$ medium under any condition resulted in minimal amounts of lactic acid production (Fig. 3c) and increased acetate production, due to the conversion of the yeast extract (Fig. 3d). In addition to the increased lactic acid production we noticed an increase in cell densities in minimal media with xylan in comparison to cultures on minimal media without xylan (Fig. 3a). In rich media no significant difference in cell densities were observed between cultures with and without xylan, likely due to high growth rates on yeast extract (Fig. 3c).

\section{Discussion}

This study was aimed at the discovery of novel industrially relevant strains that harbour saccharolytic enzymes to degrade cellulose and xylan have lactic acid as their main fermentation product and are genetically accessible. We describe the isolation of 94 facultative anaerobic Geobacillus strains that were capable of fermentation of both $\mathrm{C} 6$ and $\mathrm{C} 5$ sugars under micro-aerobic and anaerobic conditions. For isolate G. thermodenitrificans T12 direct conversion of beech wood xylan to lactic acid was demonstrated. The selection methods yielded several
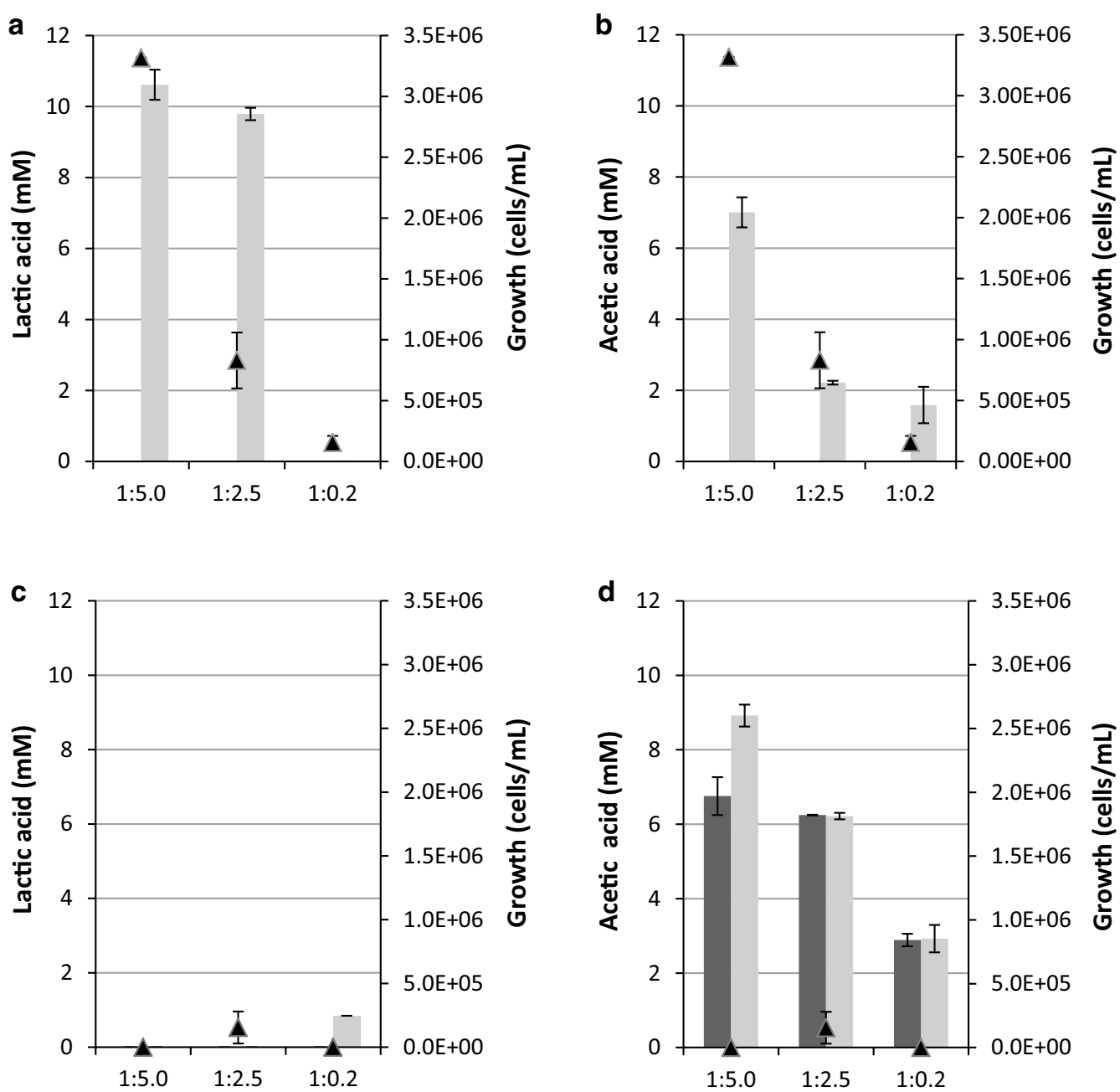

Fig. 3 Xylan fermentations by G. thermodenitrificans T12. Lactic acid production (a, c) and acetic acid production (b, d) of strain T12 on MMy (a, b) and $\mathrm{MMy}+(\mathbf{c}, \mathbf{d})$ media with xylan (light-grey bars) and without xylan (dark-grey bars). The cultures were grown in $50 \mathrm{~mL}$ Greiner tubes at pH 6.5 and $150 \mathrm{rpm}$. Ratios on the $X$-axis represent the ratio of medium and headspace during fermentation. Growth $(\mathbf{\Lambda})$ is expressed as increase of cells on xylan compared to cultures without xylan 
isolates that were capable of degrading xylan and cellulose. All strains described in this study were isolated from compost at both moderate and high temperature by repetitive growth on both CMC and xylan. It has been previously shown that Geobacillus was the dominant genus in "mature" compost [35-37]. However, it cannot be concluded if the ratio of Geobacillus species found in this study represents the composition of the Geobacillus community in the compost heap sampled, or results from selection by the sampling and isolation methods. In prior studies [17], compost heaps on the same site were sampled and screened for thermophilic organisms. The TMM media used in the study of Bosma et al. [17] contained $0.9 \mathrm{~g} \mathrm{NaNO}_{3}$ which led, at $65{ }^{\circ} \mathrm{C}$, to the isolation of mainly G. thermodenitrificans strains. When both vitamins and metals were added, a larger diversity in Geobacillus species was found. In isolations done at $60{ }^{\circ} \mathrm{C}$ without nitrate in the medium approximately half the isolates belonged to Geobacillus but no G. thermodenitrificans isolates were found (E F Bosma, unpublished data). With the selection criteria used in this study, it was anticipated that geobacilli would be isolated. The overrepresentation of G. thermodenitrificans (79\% of isolates) in this isolation procedure, however, was surprising since nitrate was excluded from the isolation media to prevent this species benefiting over other species.

All strains were isolated after repeated growth on CMC and beech wood xylan. Degradation of xylan was always detectable and most strains showed clearing zones when assayed on Congo red plates. In contrast, the results on CMC in Congo red assays appeared difficult to reproduce. Although never described for Geobacillus or closely related species, the irreproducibility is most likely caused by regulation of the expression of saccharolytic enzymes, as has been described for xylanolytic enzymes [38]. The latter study describes that the hemicellulose utilisation (HUS) locus is most likely induced by small amounts of free xylose. It is known that the coverage of the HUS locus varies substantially among Geobacillus species and even differs per strain [10]. From our study it has become clear that within geobacilli there is major variation in the regulation of the xylanolytic cassette. In apparently identical situations, the breakdown of xylan differs greatly between Geobacillus species and even between strains of the same species. Regulation of cellulase gene expression has not yet been described for Geobacilli and details of its control remain elusive. Growth is no direct evidence for the presence of extracellular cellulases although free glucose is limited in this substrate which implies at least some cellulolytic activity to be present.

When grown under micro-aerobic conditions, all isolates generated lactic acid as their main fermentation product from glucose and xylose. Acetate and succinate were always present as minor by-products, and occasionally, formate and ethanol were produced. Isolates belonging to the G. thermoglucosidans clade showed low differentiation in terms of fermentation products and amounts, whereas G. caldoxylosilyticus and G. thermodenitrificans produce quite a diverse spectrum.

Genetic accessibility was tested for three selected isolates. Strain T12 was found to be reproducibly transformable, albeit with low efficiencies of 3-5 transformants per $\mu \mathrm{g}$ of plasmid DNA. In previous research [17], only 2 of 25 strains of G. thermodenitrificans could be transformed. The transformation efficiencies of G. thermodenitrificans isolates in the latter study are in line with the efficiency of transformation described here. Efficient transformation of a $G$. thermodenitrificans strain by electroporation has been described before [16] yielding approximately $2.8 \times 10^{6}$ colonies $/ \mu \mathrm{g}$ DNA. However, this protocol resulted in only 3-5 T12 transformants/ $\mu$ g of plasmid DNA. The efficiency reported by Kananavičiute and Čitavičius [16] was obtained using plasmid DNA isolated from the same strain, circumventing possible degradation by a native restriction modification system. Conversely, there is no literature available describing a systematic approach in optimising electroporation protocols for Geobacillus species. We have optimised the transformation for $G$. thermodenitrificans $\mathrm{T} 12$ by adjusting the concentration of $\mathrm{K}_{2} \mathrm{HPO}_{4}$ in its growth media used in preparation of making the cells competent. The change of wash buffers further increased the transformation efficiency to CFU/ $\mu \mathrm{g}$ DNA of $1.7 \times 10^{4}$. With this transformation efficiency we were able to introduce the heterologous reporter gene $p h e B$ to T12. The expression of the phe $B$ gene, controlled by a constitutive promoter (PuppT12), shows the potential of strain T12 for further genetic engineering. Strain T12 was selected based on its ability to grow on CMC plates, its reproducible xylan degradation, an above average product titre on $\mathrm{C} 6$ and C5 fermentations, and its genetic accessibility, which provides opportunities to develop this strain into a host for CBP processes. To reach this potential, the organism should be engineered to produce cellulolytic enzymes.

Strain T12 was found to have an optimum $\mathrm{pH}$ between 6.5 and 7.5, and temperature of $65^{\circ} \mathrm{C}$, identical to that of isolation. When T12 is grown on pure glucose or xylose the sugar consumption rate was almost equal, whereas during co-fermentation the glucose consumption rate was approximately two to three times as high compared to the xylose consumption rate. This indicates that the presence of glucose partially inhibits xylose uptake and/ or metabolism. Reduced xylose consumption by Geobacillus in a glucose/xylose mixture has been reported before [29]. On average, hemicellulose makes up 25-35\% of lignocellulosic biomass, which makes simultaneous 
sugar uptake advantageous for the CBP economy [39]. There are many microbes capable of xylose consumption, however, most of these organisms suppress the uptake of xylose when glucose is present. This negative feedback results in sequential consumption of available sugars, leading to elongated fermentation times or accumulation of xylose in the reactor during fed-batch.

We have demonstrated the direct conversion of beech wood xylan into lactic acid by G. thermodenitrificans T12. The ratio of medium to headspace was important for this process, where increased oxygen transfer seems to positively affect xylan degradation, but negatively influences the ratio of lactic acid to acetic acid produced. Higher acetic acid production was seen with higher oxygen concentrations, while lactic acid was mostly produced in micro-aerobic conditions. The reduced degradation of xylan under high nutrient conditions $(\mathrm{MMy}+)$ was most likely caused by the repression of $x y n A$ by the global regulator CodY. It is known from B. subtilis that the CodY regulator is responsive to branched-chain amino acids (nutrient-rich conditions) [40]. A CodY orthologue has been found in the genome sequence of $G$. thermodenitrificans T12 (to be published), and two potential binding regions for CodY, based on the binding region consensus sequences from $[38,40]$, were identified in the promoter region of the T12 xynA gene (Fig. 4). For G. stearothermophilus T6, which has a xylanolytic operon similar to that of T12, CodY binding to the $x y n A$ promoter was demonstrated and its function as repressor of $x y n A$ expression was postulated [38]. Our results are in line with this hypothesis (Fig. 4c, d).

\section{Conclusions}

In conclusion, a collection of 94 Geobacillus isolates were obtained from an initial selection of 520 thermophilic organisms, by screening for lactic acid production on both C6 and C5 sugars, together with the ability to degrade xylan and/or cellulose. Genetic accesibility was confirmed and optimised for one isolate, which was designated G. thermodenitrificans T12. This strain is able

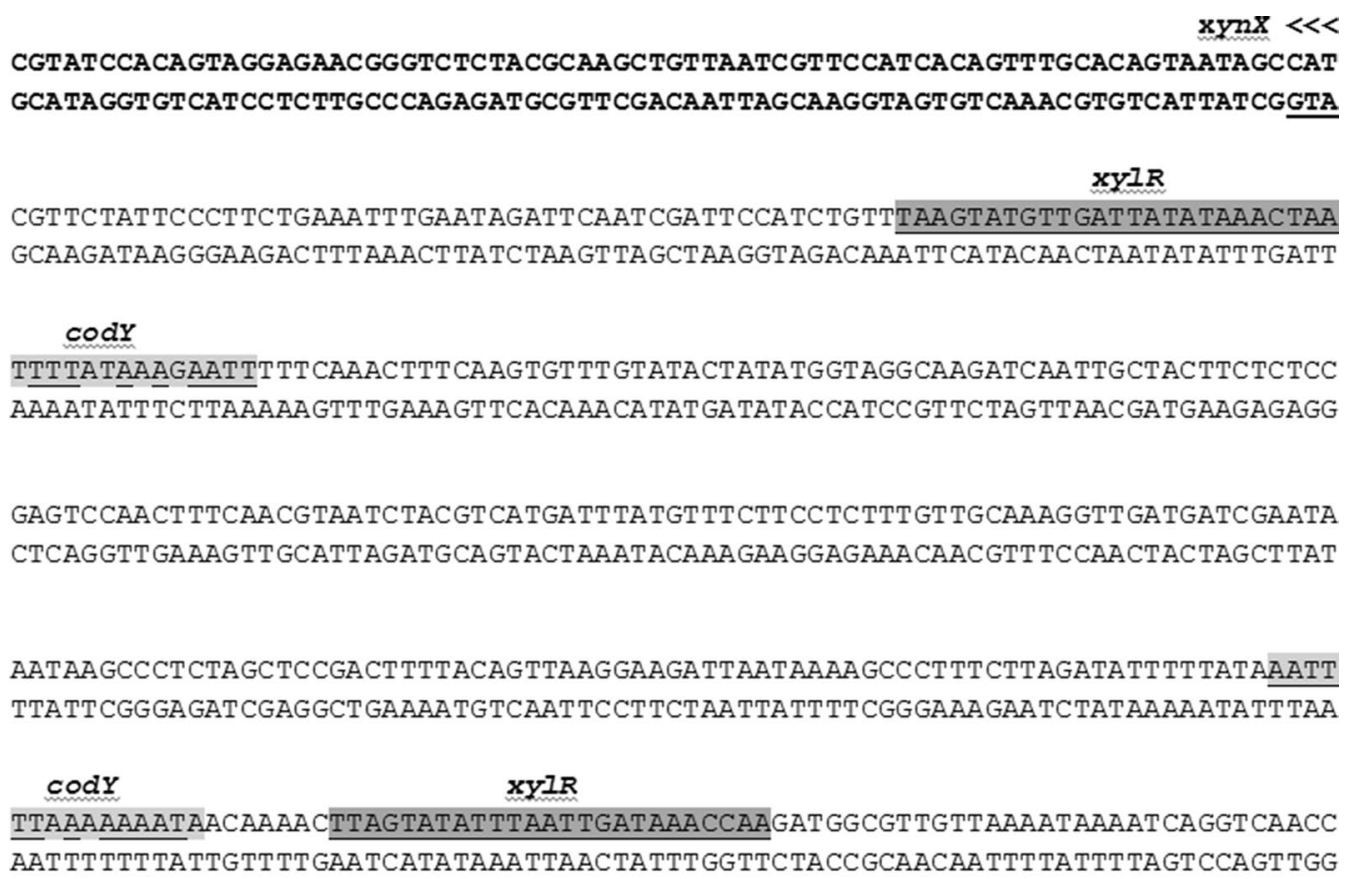

TCCCTACAAACATCT TCTTCTCGCGATAAGACACCT TCCCATTACAGGTTGGAACAAT GAAAGGAAGGGAGT GAT AGGGATGTTT GTAGAAGAAGAGCGCTATTCTGTGGAAGGGTAATGTCCAACCTTGTTACTTTCCTTCCCTCACTA 
to grow on CMC plates, although Congo red assays are inconsistent. Strain T12 is capable of fermenting both xylose and glucose simultaneously with lactic acid as its main fermentation product. In addition, beechwood xylan was directly converted to lactic acid. The capacity of strain T12 to ferment xylan together with its genetic accessibility makes G. thermodenitrificans $\mathrm{T} 12$ a potential candidate for consolidated bioprocessing.

\section{Additional files}

Additional file 1: Figure S1. Sequence of the PuppT12 promoter including the first ATG codon of the uracil phosphoribosyltransferase gene.

Additional file 2: Table S1. Overview of the number of isolates recovered from the first isolation. Overview of the number of isolates recovered from the first isolation on CTVMY-CMC and CTVM-CMC media after $20 \mathrm{~h}, 48 \mathrm{~h}$ and $88 \mathrm{~h}$. The $\mathrm{pH}$ was set at 6.5 and plates were incubated at $65^{\circ} \mathrm{C}$. Dilution series were plated from compost that had been shaken at $150 \mathrm{rpm}$ for $3 \mathrm{~h}$ in the same medium and temperature.

Additional file 3: Table S2. HPLC data from isolates ranked on total organic acid production and total lactic acid production on cellobiose (C6).

Additional file 4: Table S3. HPLC data from isolates ranked on total organic acid production and total lactic acid production on xylose (C5).

Additional file 5: Figure S2. G. thermodenitrificans T12 transformed with pNW33n (A1) and pNW33n+ pheB (B1). Colonies were sprayed with $100 \mathrm{mM}$ catechol and incubated for $5 \mathrm{~min}$ at $55^{\circ} \mathrm{C}$. The colony containing pNW33n did not show any colour formation (A2) while the colony with the pheB gene under control of the constitutive uracil phosphoribosyltransferase promoter (PuppT12) shows a yellow colour (B2) indicating the conversion of catechol to 2-hydroxymuconic semialdehyde.

\section{Abbreviations}

PLA: poly lactic acid; CBP: consolidated bioprocessing; HUS locus: hemicellulose utilisation locus; NCBI: National Centre For Biotechnology Information; CTVM: cellulolytic thermophile vitamin medium; MM: minimal medium; LB: luria bertani; CMC: carboxymethyl cellulose; Glc: glucose; OD: optical density; HPLC: high pressure liquid chromatography; O/N: overnight; RI: refractive index; CFU/ug DNA: colony forming units per microgram of plasmid DNA; Ptd: pulse time duration.

\section{Authors' contributions}

MD designed and performed the study, analysed the data and drafted the manuscript. AW performed fermentations, prepared corresponding data and assisted in drafting the manuscript. WV and JO assisted in the interpretation of data, coordinated the study and revised the manuscript. RvK assisted in the design of the study, analysis and interpretation of data, coordinated the study and revised the manuscript. All authors read and approved on the final manuscript.

\section{Author details}

${ }^{1}$ Laboratory of Microbiology, Wageningen University, Stippeneng 4, 6708 WE Wageningen, The Netherlands. ${ }^{2}$ Corbion, Arkselsedijk 46, 4206 AC Gorinchem, The Netherlands.

\section{Acknowledgements}

We thank Willem van Harten from Recom Ede for allowing us to sample their compost and Sofia Thomaidou and loanna Papakosta for their excellent technical assistance.

\section{Competing interests}

The authors declare that they have no competing interests. RvK is employed by Corbion (Gorinchem, The Netherlands).

\section{Funding}

This work was financially supported by BE-Basic (www.be-basic.org) and Corbion.

Received: 9 May 2016 Accepted: 20 September 2016

Published online: 06 October 2016

\section{References}

1. Beauprez JJ, De Mey M, Soetaert WK. Microbial succinic acid production: natural versus metabolic engineered producers. Process Biochem. 2010:45(7):1103-14

2. Abdel-Rahman MA, Tashiro Y, Sonomoto K. Lactic acid production from lignocellulose-derived sugars using lactic acid bacteria: overview and limits. J Biotechnol. 2011;156(4):286-301.

3. Davis R, Tao L, Tan ECD, Biddy MJ, Beckham GT, Scarlata C, Jacobson J, Cafferty K, Ross J, Lukas J, et al. Process design and economics for the conversion of lignocellulosic biomass to hydrocarbons: dilute-acid and enzymatic deconstruction of biomass to sugars and biological conversion of sugars to hydrocarbons. In.: NREL; 2013.

4. Lynd LR, ZyI WHV, McBride JE, Laser M. Consolidated bioprocessing of cellulosic biomass: an update. Curr Opin Biotechnol. 2005:16(5):577-83

5. Blumer-Schuette SE, Brown SD, Sander KB, Bayer EA, Kataeva I, Zurawski JV, Conway JM, Adams MWW, Kelly RM. Thermophilic lignocellulose deconstruction. FEMS Microbiol Rev. 2014;38(3):393-448.

6. Schuster BG, Chinn MS. Consolidated bioprocessing of lignocellulosic feedstocks for ethanol fuel production. Bioenerg Res. 2013;6(2):416-35.

7. Nazina TN, Tourova TP, Poltaraus AB, Novikova EV, Grigoryan AA, Ivanova AE, Lysenko AM, Petrunyaka WV, Osipov GA, Belyaev SS, et al. Taxonomic study of aerobic thermophilic bacilli: descriptions of Geobacillus subterraneus gen. nov., sp. nov. and Geobacillus uzenensis sp. nov. from petroleum reservoirs and transfer of Bacillus stearothermophilus, Bacillus thermocatenulatus, Bacillus thermoleovorans, Bacillus kaustophilus, Bacillus thermoglucosidasius and Bacillus thermodenitrificans to Geobacillus as the new combinations G. stearothermophilus, G. thermocatenulatus, G. thermoleovorans, G. kaustophilus, G. thermoglucosidasius and G. thermodenitrifcans. Int J Syst Evol Microbiol. 2001;51(2):433-46.

8. Rastogi G, Bhalla A, Adhikari A, Bischoff KM, Hughes SR, Christopher LP, Sani RK. Characterization of thermostable cellulases produced by Bacillus and Geobacillus strains. Bioresour Technol. 2010;101(22):8798-806

9. Bhalla A, Bischoff KM, Uppugundla N, Balan V, Sani RK. Novel thermostable end-oxylanase cloned and expressed from bacterium Geobacillus sp. WSUCF1. Biores Technol. 2014;165(C):314-8.

10. De Maayer P, Brumm PJ, Mead DA, Cowan DA. Comparative analysis of the Geobacillus hemicellulose utilization locus reveals a highly variable target for improved hemicellulolysis. BMC Genom. 2014;15(1):1.

11. Tai SK, Lin HPP, Kuo J, Liu JK. Isolation and characterization of a cellulolytic Geobacillus thermoleovorans T4 strain from sugar refinery waste water. Extremophiles. 2004;8(5):345-9.

12. Rastogi G, Muppidi G, Gurram R, Adhikari A, Bischoff K, Hughes S, Apel W, Bang S, Dixon D, Sani R. Isolation and characterization of cellulosedegrading bacteria from the deep subsurface of the Homestake gold mine, Lead, South Dakota, USA. J Ind Microbiol Biotechnol. 2009;36(4):585-98.

13. Ng IS, Li CW, Yeh YF, Chen PT, Chir JL, Ma CH, Yu SM, Ho THD, Tong CG. A novel endo-glucanase from the thermophilic bacterium Geobacillus sp. 70PC53 with high activity and stability over a broad range of temperatures. Extremophiles. 2009;13(3):425-35.

14. Cripps RE, Eley K, Leak DJ, Rudd B, Taylor M, Todd M, Boakes S, Martin S, Atkinson T. Metabolic engineering of Geobacillus thermoglucosidasius for high yield ethanol production. Metab Eng. 2009;11(6):398-408.

15. Bartosiak-Jentys J, Hussein AH, Lewis CJ, Leak DJ. Modular system for assessment of glycosyl hydrolase secretion in Geobacillus thermoglucosidasius. Microbiology (United Kingdom). 2013;159(PART7):1267-75.

16. Kananavičiute R, Čitavičius D. Genetic engineering of Geobacillus spp. J Microbiol Methods. 2015;11:31-9. 
17. Bosma EF, van de Weijer AHP, Daas MJA, van der Oost J, de Vos WM, van Kranenburg R. Isolation and screening of thermophilic bacilli from compost for electro transformation and fermentation: characterization of bacillus smithii ET 138 as a new biocatalyst. Appl Environ Microbiol. 2015;81(5):1874-83.

18. Studholme DJ. Some (bacilli) like it hot: genomics of Geobacillus species. Microb Biotechnol. 2015;8(1):40-8

19. Fong J, Svenson C, Nakasugi K, Leong C, Bowman J, Chen B, Glenn D, Neilan B, Rogers P. Isolation and characterization of two novel ethanoltolerant facultative-anaerobic thermophilic bacteria strains from waste compost. Extremophiles. 2006;10(5):363-72.

20. Sizova MV, Izquierdo JA, Panikov NS, Lynd LR. Cellulose- and xylandegrading thermophilic anaerobic bacteria from biocompost. Appl Environ Microbiol. 2011;77(7):2282-91.

21. Muyzer G, Teske A, Wirsen CO, Jannasch HW. Phylogenetic relationships of Thiomicrospira species and their identification in deep-sea hydrothermal vent samples by denaturing gradient gel electrophoresis of 165 rDNA fragments. Arch Microbiol. 1995;164(3):165-72

22. Tamura K, Stecher G, Peterson D, Filipski A, Kumar S. MEGA6: molecular evolutionary genetics analysis version 6.0. Mol Biol Evol. 2013;30(12):2725-9.

23. Edgar RC. MUSCLE: multiple sequence alignment with high accuracy and high throughput. Nucleic Acids Res. 2004;32(5):1792-7.

24. Waterhouse AM, Procter JB, Martin DMA, Clamp M, Barton GJ. Jalview version 2-A multiple sequence alignment editor and analysis work bench. Bioinformatics. 2009;25(9):1189-91.

25. Saitou N, Nei M. The neighbor-joining method: a new method for reconstructing phylogenetic trees. Mol Biol Evol. 1987;4(4):406-25.

26. Felsenstein J. Confidence limits on phylogenies: an approach using the bootstrap. Evolution. 1985;39:783-91.

27. Taylor MP, Eley KL, Martin S, Tuffin MI, Burton SG, Cowan DA. Thermophilic ethanologenesis: future prospects for second-generation bioethanol production. Trends Biotechnol. 2009;27(7):398-405

28. Narumi I, Sawakami K, Nakamoto S, Nakayama N, Yanagisawa T, Takahashi $\mathrm{N}$, Kihara H. A newly isolated Bacillus stearotheromophilus K1041 and its transformation by electroporation. Biotechnol Tech. 1992;6(1):83-6.

29. Tang YJ, Sapra R, Joyner D, Hazen TC, Myers S, Reichmuth D, Blanch H, Keasling JD. Analysis of metabolic pathways and fluxes in a newly discovered thermophilic and ethanol-tolerant geobacillus strain. Biotechnol Bioeng. 2009;102(5):1377-86.
30. Taylor MP, Esteban CD, Leak DJ. Development of a versatile shuttle vector for gene expression in Geobacillus spp. Plasmid. 2008;60(1):45-52.

31. Blanchard K, Robic S, Matsumura I. Transformable facultative thermophile Geobacillus stearothermophilus NUB3621 as a host strain for metabolic engineering. Appl Microbiol Biotechnol. 2014;98(15):6715-23.

32. Lin PP, Rabe KS, Takasumi JL, Kadisch M, Arnold FH, Liao JC. Isobutanol production at elevated temperatures in thermophilic Geobacillus thermoglucosidasius. Metab Eng. 2014;24:1-8.

33. Bartosiak-Jentys J, Eley K, Leak DJ. Application of pheB as a reporter gene for Geobacillus spp, enabling qualitative colony screening and quantitative analysis of promoter strength. Appl Environ Microbiol. 2012;78(16):5945-7.

34. Mishima M, Iwata K, Nara K, Matsui T, Shigeno T, Omori T. Cultivation characteristics of denitrification by thermophilic Geobacillus sp. strain TDN01. J Gen Appl Microbiol. 2009;55(2):81-6.

35. Takaku H, Kodaira S, Kimoto A, Nashimoto M, Takagi M. Microbial communities in the garbage composting with rice hull as an amendment revealed by culture-dependent and -independent approaches. J Biosci Bioeng. 2006;101(1):42-50.

36. Tian W, Sun Q, Xu D, Zhang Z, Chen D, Li C, Shen Q, Shen B. Succession of bacterial communities during composting process as detected by $16 \mathrm{~S}$ rRNA clone libraries analysis. Int Biodeterior Biodegrad. 2013;78:58-66.

37. Ryckeboer J, Mergaert J, Coosemans J, Deprins K, Swings J. Microbiological aspects of biowaste during composting in a monitored compost bin. J Appl Microbiol. 2003;94(1):127-37.

38. Shulami S, Shenker O, Langut Y, Lavid N, Gat O, Zaide G, Zehavi A, Sonenshein AL, Shoham Y. Multiple regulatory mechanisms control the expression of the Geobacillus stearothermophilus gene for extracellular xylanase. J Biol Chem. 2014;289(37):25957-75.

39. Murciano Martínez P, Bakker R, Harmsen P, Gruppen H, Kabel M. Importance of acid or alkali concentration on the removal of xylan and lignin for enzymatic cellulose hydrolysis. Ind Crops Prod. 2015;64:88-96.

40. Sonenshein AL. CodY, a global regulator of stationary phase and virulence in Gram-positive bacteria. Curr Opin Microbiol. 2005;8(2):203-7.

\section{Submit your next manuscript to BioMed Central and we will help you at every step:}

- We accept pre-submission inquiries

- Our selector tool helps you to find the most relevant journal

- We provide round the clock customer support

- Convenient online submission

- Thorough peer review

- Inclusion in PubMed and all major indexing services

- Maximum visibility for your research

Submit your manuscript at www.biomedcentral.com/submit
BioMed Central 